\title{
Entransy dissipation minimization for optimization of heat exchanger design
}

\author{
LI XueFang, GUO JiangFeng, XU MingTian* \& CHENG Lin \\ Institute of Thermal Science and Technology, Shandong University, Jinan 250061, China
}

Received July 16, 2010; accepted March 15, 2011

\begin{abstract}
In this paper, by taking the water-water balanced counterflow heat exchanger as an example, the entransy dissipation theory is applied to optimizing the design of heat exchangers. Under certain conditions, the optimal duct aspect ratio is determined analytically. When the heat transfer area or the duct volume is fixed, analytical expressions of the optimal mass velocity and the minimal entransy dissipation rate are obtained. These results show that to reduce the irreversible dissipation in heat exchangers, the heat exchange area should be enlarged as much as possible, while the mass velocity should be reduced as low as possible.
\end{abstract}

entransy, heat exchanger, optimization design

Citation: $\quad$ Li X F, Guo J F, Xu M T, et al. Entransy dissipation minimization for optimization of heat exchanger design. Chinese Sci Bull, 2011, 56: 2174-2178, doi: 10.1007/s11434-011-4489-9

As fossil fuels are gradually depleted, fuel prices will surely rise. As a result, energy shortages are foreseen as a detrimental factor that could restrict economic and social development. Improving energy use efficiency is one of the most effective ways to address an energy crisis. Heat exchangers are widely applied in the chemical industries, petroleum refineries, power engineering, food industries, and many other areas. Therefore, it will be of great value to reduce needless energy dissipation and improve the performance of heat exchangers by optimizing their design.

The objectives in heat exchanger design optimization can be classified into two groups: one is minimizing costs of heat exchangers [1-5]; the other is minimizing irreversibility based on the second law of thermodynamics that occurs in heat exchangers [6-10]. The first approach can reduce costs, but possibly at the expense of sacrificing heat exchanger performance [11]. As representative of the second approach, entropy generation minimization suffers from so-called "entropy generation paradox" $[8,12]$.

By analogy with electrical conduction, Guo et al. defined a new physical concept, entransy, which describes heat

\footnotetext{
*Corresponding author (email: mingtian@sdu.edu.cn)
}

transfer capability [13]. Based on this concept, the equivalent thermal resistance of a heat exchanger was defined to quantify heat transfer irreversibility in heat exchangers [14]. Chen et al. applied entransy dissipation theory to the volume-to-point conduction problem [15]. Guo et al. defined an entransy dissipation number to evaluate heat exchanger performance that not only avoids the "entropy generation paradox" resulting from the entropy generation number, but can also characterize the overall performance of heat exchangers [12]. Xu et al. [16] developed an expression of the entransy dissipation induced by flow friction under finite pressure drop in a heat exchanger.

The present work, based on expressions of entransy dissipation from heat conduction under finite temperature differences and flow friction under finite pressure drops [14, $16]$, and on the dimensionless method proposed by Guo et al. [12], defines an overall entransy dissipation numbers. The minimum overall entransy dissipation number is then taken as an objective function. Under certain assumptions we attempt to prove that since the variation in the duct aspect ratio or mass velocity has opposing effects on the two types of entransy dissipations caused by heat conduction under finite temperature difference and the flow friction 
under finite pressure drop, respectively, there is a corresponding optimum in duct aspect ratio or mass velocity. We also develop analytically expressions for the optimal duct aspect ratio and mass velocity of a heat exchanger that are useful for design optimization.

\section{Entransy dissipation number}

The entransy is defined as one-half the product of heat capacity and temperature [13]:

$$
E_{h}=\frac{1}{2} Q_{v h} T=\frac{1}{2} M c_{p} T^{2},
$$

where $T$ is the temperature, $Q_{v h}$ is the heat capacity at constant volume, and $c_{p}$ is the specific heat at constant pressure. Now, using the water-water balanced counter-flow heat exchanger as an example, we attempt to discuss the entransy dissipation in heat exchangers.

Assume that both the hot and cold fluids are incompressible. The inlet temperature and pressure of the hot and cold fluids are denoted as $T_{1}, P_{1}$ and $T_{2}, P_{2}$, respectively. Similarly the outlet temperature and pressure are $T_{1 \text {,out }}, P_{1 \text {,out }}$ and $T_{2, \text { out }}, P_{2 \text {,out }}$. For the balanced heat exchanger, the heat capacity rate ratio satisfies condition $C^{*}=(\dot{m} c)_{2} /(\dot{m} c)_{1}=1$

(where $\dot{m}$ is the mass flow rate). For the one-dimensional heat exchanger considered in the present work, the usual assumptions such as steady flow, no heat exchange with environment, and ignoring changes in kinetic and potential energies as well as the longitudinal conduction are made.

In the heat exchanger, there mainly exist two kinds of irreversibility: the first is heat conduction under finite temperature differences and the second is flow friction under finite pressure drops. The entransy dissipation rate caused by heat conduction under a finite temperature difference is written as [14]

$$
\begin{aligned}
\dot{E}_{T}= & {\left[\frac{1}{2}(\dot{m} c)_{1} T_{1}^{2}+\frac{1}{2}(\dot{m} c)_{2} T_{2}^{2}\right] } \\
& -\left[\frac{1}{2}(\dot{m} c)_{1} T_{1, \text { out }}^{2}+\frac{1}{2}(\dot{m} c)_{2} T_{2, \text { out }}^{2}\right] .
\end{aligned}
$$

The corresponding entransy dissipation number is defined as [12]

$$
\dot{E}_{T}^{*}=\frac{\dot{E}_{T}}{Q\left(T_{1}-T_{2}\right)}=\frac{\dot{E}_{T}}{\varepsilon(\dot{m} c)_{1}\left(T_{1}-T_{2}\right)^{2}},
$$

where $Q$ is the heat transfer rate, $\varepsilon$ is the heat exchanger effectiveness which is defined as the ratio of the actual heat transfer rate to the maximum possible heat transfer rate. The entransy dissipation due to flow friction under a finite pressure drop is expressed as [16]

$$
\dot{E}_{P}=\frac{\dot{m}_{1} \Delta P_{1}}{\rho_{1}} \frac{T_{1, \text { out }}-T_{1}}{\ln T_{1, \text { out }}-\ln T_{1}}+\frac{\dot{m}_{2} \Delta P_{2}}{\rho_{2}} \frac{T_{2, \text { out }}-T_{2}}{\ln T_{2, \text { out }}-\ln T_{2}},
$$

where $\Delta P_{1}$ and $\Delta P_{2}$ refer to the pressure drops in the hot and cold water, respectively; $\rho_{1}$ and $\rho_{2}$ are their corresponding densities. Putting in dimensionless form leads to

$$
\begin{aligned}
\dot{E}_{P}^{*}= & \frac{-\Delta P_{1}}{(\rho c)_{1}\left(T_{1}-T_{2}\right)} \frac{1}{\ln \frac{T_{2}}{T_{1}}\left[1-(1-\varepsilon) \frac{T_{2}-T_{1}}{T_{2}}\right]} \\
& +\frac{\Delta P_{2}}{(\rho c)_{2}\left(T_{1}-T_{2}\right)} \frac{1}{\ln \frac{T_{1}}{T_{2}}\left[1+(1-\varepsilon) \frac{T_{2}-T_{1}}{T_{1}}\right]},
\end{aligned}
$$

which is called the entransy dissipation number due to flow friction. Assuming that the heat exchanger behaves as a nearly ideal heat exchanger, then $(1-\varepsilon)$ is considerably smaller than unity [17]. For a water-water heat exchanger under usual operating conditions, the inlet temperature difference between hot and cold water, $\Delta T=T_{1}-T_{2}$, is less than $100 \mathrm{~K}$, hence $\Delta T / T_{i}<100 / 273 \approx 0.366(i=1,2)$. There fore, eq. (5) can be simplified to

$$
\dot{E}_{P}^{*}=\frac{\Delta P_{1}}{(\rho c)_{1}\left(T_{1}-T_{2}\right)} \frac{1}{\ln \frac{T_{1}}{T_{2}}}+\frac{\Delta P_{2}}{(\rho c)_{2}\left(T_{1}-T_{2}\right)} \frac{1}{\ln \frac{T_{1}}{T_{2}}} .
$$

Accordingly, the overall entransy dissipation number becomes

$$
\begin{aligned}
\dot{E}^{*}=\dot{E}_{T}^{*}+\dot{E}_{P}^{*}= & (1-\varepsilon)+\frac{\Delta P_{1}}{(\rho c)_{1}\left(T_{1}-T_{2}\right)} \frac{1}{\ln \frac{T_{1}}{T_{2}}} \\
& +\frac{\Delta P_{2}}{(\rho c)_{2}\left(T_{1}-T_{2}\right)} \frac{1}{\ln \frac{T_{1}}{T_{2}}}
\end{aligned}
$$

For a typical water-water balanced heat exchanger, the number of heat transfer units $N t u$ can be introduced, which approaches infinity as the effectiveness tends to unity. Since $C^{*}=1$, the effectiveness is [17]

$$
\varepsilon=\frac{N t u}{1+N t u},
$$

where the number of heat transfer units is defined as

$$
N t u=\frac{U A}{\dot{m} c_{p}} .
$$

Here $U$ is the overall heat transfer coefficient, and $A$ is the heat transfer area. Assuming that the heat conduction resistance of the solid wall can be neglected, compared with the convective heat transfer, then it is appropriate to replace $U$ with the convective heat transfer coefficient $h$. Therefore,

$$
\frac{1}{U A}=\frac{1}{(h A)_{1}}+\frac{1}{(h A)_{2}},
$$


or

$$
\frac{1}{N t u}=\frac{1}{N t u_{1}}+\frac{1}{N t u_{2}},
$$

where $h_{1}$ and $h_{2}$ are the convective heat transfer coefficients of the hot and cold fluids, respectively, and $N t u_{i}=(h A)_{i} /(\dot{m} c)_{i}(i=1,2)$. In the nearly ideal heat exchanger limit, Ntu $>>1$, that is [17]

$$
1-\varepsilon \approx \frac{1}{N t u},
$$

from eq. (7) the overall entransy dissipation number is expressed as

$$
\begin{aligned}
\dot{E}^{*}= & {\left[\frac{1}{N t u_{1}}+\frac{\Delta P_{1}}{(\rho c)_{1}\left(T_{1}-T_{2}\right)} \frac{1}{\ln \frac{T_{1}}{T_{2}}}\right] } \\
& +\left[\frac{1}{N t u_{2}}+\frac{\Delta P_{2}}{(\rho c)_{2}\left(T_{1}-T_{2}\right)} \frac{1}{\ln \frac{T_{1}}{T_{2}}}\right] .
\end{aligned}
$$

The two terms on the right of eq. (11) correspond to the entransy dissipations of two sides of heat transfer surfaces. For each side, the entransy dissipation number can be expressed as follows:

$$
\dot{E}_{i}^{*}=\frac{1}{N t u_{i}}+\frac{P_{i}}{(\rho c)_{i}\left(T_{1}-T_{2}\right) \ln \frac{T_{1}}{T_{2}}} \frac{\Delta P_{i}}{P_{i}} \quad(i=1,2) .
$$

It is evident that the first term accounts for the entransy dissipation from the heat conduction under finite temperature difference and the second for the entransy dissipation from flow friction under finite pressure drop. For simplicity, we now use $\dot{E}^{*}$ instead of $\dot{E}_{i}^{*}$ to denote the entransy dissipation number for each side of the heat exchanger surface.

Note that in the derivations of eqs. (2) and (4), there is no assumption that the flow is laminar [14,16]; therefore, the above results are applicable for both laminar and turbulent flows.

\section{Parameter optimization}

Theoretically, the exchanger effectiveness increases when the irreversible dissipation in the heat exchanger decreases. Since the entransy dissipation can be used to describe these irreversible dissipations $[18,19]$, therefore we seek optimums in duct aspect ratio and mass velocity by minimizing the entransy dissipation number $\dot{E}^{*}$ based on eq. (12).

\subsection{The optimum aspect ratio}

Although the entransy dissipation number on one side of a heat transfer surface can be expressed as the sum of the contributions of the heat conduction under the finite temperature difference and flow friction under the finite pressure drop, the effects of these two factors on heat exchanger irreversibility are strongly coupled through the geometric parameters of the heat exchanger tube residing on that side. Therefore, based on entransy dissipation minimization, it is possible to obtain optimal geometric parameters of the heat exchanger such as the optimal duct aspect ratio.

Recall the definition of the Stanton number $\operatorname{St}\left((\operatorname{Re})_{D}, P r\right)$ and friction factor $f\left((\operatorname{Re})_{D}\right)$ :

$$
\begin{gathered}
N t u=\frac{4 L}{D} S t, \\
\frac{\Delta P}{P}=f \frac{4 L}{D} \frac{G^{2}}{2 \rho P},
\end{gathered}
$$

where $G=\dot{m} / A$ is the mass velocity, $L$ is the flow path length and $D$ is the duct hydraulic diameter. Introducing the dimensionless mass velocity, $G_{*}=G / \sqrt{2 \rho P}$, letting

$$
\tau^{2}=\frac{P}{(\rho c)\left(T_{1}-T_{2}\right) \ln \frac{T_{1}}{T_{2}}},
$$

and substituting eqs. (13) and (14) into eq. (12), we obtain

$$
\dot{E}^{*}=\frac{1}{\frac{4 L}{D} S t}+\tau^{2} f \frac{4 L}{D} G_{*}^{2} .
$$

Clearly, the duct aspect ratio $4 L / D$ has opposing effects on the two terms of the right side of eq. (15). Therefore, there exists an optimal duct aspect ratio to minimize the entransy number. When the Reynolds number and mass velocity are fixed, minimizing the entransy dissipation number leads to the following expression for this optimum:

$$
\left(\frac{4 L}{D}\right)_{\mathrm{opt}}=\frac{1}{\tau G_{*}(f S t)^{1 / 2}}
$$

The corresponding minimum entransy dissipation number is

$$
\dot{E}_{\min }^{*}=2 \tau G_{*}\left(\frac{f}{S t}\right)^{1 / 2} .
$$

From eqs. (16) and (17), one can see that the optimal duct aspect ratio decreases as the mass velocity $G_{*}$ increases, and the minimum entransy dissipation number is directly proportional to the dimensionless mass velocity. Note that the minimum entransy dissipation number is also dependent on the Reynolds number via $f$ and $S t$. However, the impact of the Reynolds number on the minimum entransy dissipation number is very weak since for many heat transfer surfaces the ratio of the friction factor to the Stanton number does not have a significant change as the Reynolds number varies [17]. Therefore, the minimum entransy dissipation 
number is mainly determined by the selected dimensionless mass velocity. Obviously, the smaller the mass velocity, the longer the working fluid remains on the heat transfer surface and the lower the irreversible dissipations in the heat exchanger.

\subsection{Parameter optimization under fixed heat transfer area}

In designing a heat exchanger, the heat transfer area is an important consideration when it accounts for most of the total cost of a heat exchanger. Thus in this subsection, we discuss design optimization of the heat exchanger with a fixed heat transfer area.

From the definition of the hydraulic diameter, the heat transfer area for one side is

$$
A=\frac{4 L}{D} A_{c},
$$

where $A_{c}$ is the duct cross-section. This expression can be put in dimensionless form as

$$
A_{*}=\frac{4 L}{D} G_{*}^{-1},
$$

where $A *$ is the dimensionless heat transfer area, $A *=$ $(2 \rho P)^{1 / 2} A / \dot{m}$. Substituting eq. (18) into eq. (15) yields

$$
\dot{E}^{*}=\frac{1}{A_{*} S t} G_{*}^{-1}+\tau^{2} f A_{*} G_{*}^{3}
$$

Obviously, the dimensionless mass velocity has an opposing effect on the two terms of the right side of eq.(19); thus, there exists an optimal dimensionless mass velocity which allows the entropy dissipation number to reach a minimum value when $A *$ and Reynolds number $(R e)_{D}$ are given. Solving this optimization problem yields

$$
\begin{aligned}
& G_{*, \text { opt }}=\left(\frac{1}{3 A_{*}^{2} \tau^{2} f S t}\right)^{1 / 4}, \\
& \dot{E}_{\text {min }}^{*}=4\left(\frac{\tau^{2} f}{27 A_{*}^{2} S t^{3}}\right)^{1 / 4} .
\end{aligned}
$$

Eqs. (20) and (21) give the optimal dimensionless mass velocity and the minimum entransy dissipation number, respectively, under fixed $A *$ and Reynolds number $(R e)_{D}$. From these two equations, the larger heat transfer area clearly corresponds to the smaller mass velocity and lower entransy dissipation rates. Hence, to reduce the irreversible dissipation occurring in a heat exchanger, the largestpossible heat transfer area should be adopted under the allowable conditions.

If $\dot{E}^{*}$ and $(R e)_{D}$ are given, the minimum heat transfer area is

$$
A_{*, \min }=\frac{16}{3^{3 / 2}} \frac{\tau f^{1 / 2}}{\dot{E}^{* 2} S t^{3 / 2}},
$$

with

$$
\left(\frac{4 L}{D}\right)_{\mathrm{opt}}=\frac{4}{3} \frac{1}{\dot{E}^{*} S t}
$$

From eqs. (22) and (23), one can see that a low entransy dissipation rate corresponds to large heat transfer area or duct aspect ratio. Eqs. (21) and (22) are identical, providing an expression for the minimum attainable value for the product $A_{*}^{1 / 2} \dot{E}^{*}$ under the given Reynolds number.

\subsection{Parameter optimization under fixed duct volume}

In some space-limited situations, such as in marine and aerospace applications, space occupied by a heat exchanger is an important constraint on the heat exchanger design. Therefore, in this subsection, we discuss design optimization of heat exchangers under the fixed duct volume constraint.

The duct volume $V=L A_{c}$ can be written as

$$
V_{*}=\frac{4 L}{D}(R e)_{D} G_{*}^{-2},
$$

where $V_{*}$ is the dimensionless volume, $V_{*}=8 V P /(v \dot{m})$, $v$ is the kinematic viscosity. Substituting eq. (24) into eq. (15) and rearranging the resulting equation, we obtain

$$
\dot{E}^{*}=\frac{(R e)_{D}}{V_{*} S t} G_{*}^{-2}+\tau^{2} f \frac{V_{*}}{(R e)_{D}} G_{*}{ }^{4} .
$$

Similar to eq. (19), the dimensionless mass velocity has an opposing effect on the two terms of the right side of Eq. (25). Therefore, there exists an optimal dimensionless mass velocity that allows the entransy dissipation number to obtain a minimum value when $V_{*}$ and Reynolds number $(R e)_{D}$ are given. Solving this optimization problem yields

$$
\begin{aligned}
G_{*, \text { opt }} & =\left(\frac{(R e)_{D}^{2}}{2 V_{*}^{2} \tau^{2} f S t}\right)^{1 / 6}, \\
\dot{E}_{\text {min }}^{*} & =3\left(\frac{(R e)_{D} \tau^{2} f}{4 V_{*} S t^{2}}\right)^{1 / 3} .
\end{aligned}
$$

Eqs. (26) and (27) are formulas for the optimal dimensionless mass velocity and the minimal entransy dissipation number, respectively, under fixed $V_{*}$ and Reynolds number $(R e)_{D}$. From eqs. (26) and (27), one can see that the largest-possible duct volume leads to the lowest entransy dissipation rate and the smallest mass velocity. Obviously a restricted duct volume imposes a limit on the possible value of the minimum entransy dissipation rate. 
When $\dot{E}^{*}$ and $(R e)_{D}$ are fixed, the minimum duct volume is

$$
V_{*, \min }=\frac{27}{4} \frac{(R e)_{D} \tau^{2} f}{\dot{E}^{* 3} S t^{2}}
$$

Eqs. (27) and (28) are equivalent and yield an expression for the minimal attainable value for the product $\dot{E}^{*} V_{*}^{1 / 3}$ under the fixed Reynolds number.

\section{Concluding remarks}

As exemplified by the water-water counter-flow heat exchanger, the present work proved that there exists an optimal duct aspect ratio for heat exchangers under a fixed Reynolds number and mass velocity when the entransy dissipation number is taken as the performance evaluation criterion. Furthermore, the formula for the optimal duct aspect ratio was obtained analytically. Under constraints of fixed heat transfer area (or duct volume) and Reynolds number, it was shown that there is an optimal dimensionless mass velocity; for which an analytical expression was also given. The results indicated that to reduce irreversible dissipations in heat exchangers, largest-possible heat transfer areas and lowest-possible mass velocities should be adopted. This conclusion is in agreement with numerical results obtained by design optimization of the shell-and-tube heat exchanger based on the entransy dissipation number as the objective function [20].

From the results obtained in this study, it can be seen that the traditional heat exchanger design optimizations based on total cost as an objective function usually sacrifice heat exchanger performance. This issue has been demonstrated by numerical results [11]. From the analysis in [11] one can see that a little improvement in heat exchanger performance can lead to large gains in terms of energy saving and environmental protection. Hence, in heat exchanger design, reduction in total cost and improvement in heat exchanger performance should be treated equally. The present work will be useful to drive new research in this direction.

This work was supported by the National Basic Research Program of China (2007CB206900) and International Science and Technology Cooperation Project of Shandong Province (2008GJHZ20701).
1 Selbas R, Kizilkan O, Reppich M. A new design approach for shell-and-tube heat exchangers using genetic algorithms from economic point of view. Chem Eng Process, 2006, 45: 268-275

2 Wildi -Tremblay P, Gosselin L. Minimizing shell-and-tube heat exchanger cost with genetic algorithms and considering maintenance. Int J Energ Res, 2007, 31: 867-885

3 Allen B, Gosselin L. Optimal geometry and flow arrangement for minimizing the cost of shell-and-tube condensers. Int J Energ Res, 2008, 32: 958-969

4 Babu B V, Munawar S A. Differential evolution strategies for optimal design of shell-and-tube heat exchanger. Chem Eng Sci, 2007, 62: 3720-3739

5 Caputo A C, Pelagagge P M, Salini P. Heat exchanger design based on economic optimisation. Appl Therm Eng, 2008, 28: 1151-1159

6 Yilmaz M, Sara O N, Karsli S. Performance evaluation criteria for heat exchangers based on second law analysis. Exergy Int J, 2001, 1: 278-294

7 Bejan A. Entropy generation minimization: The new thermodynamics of finite-size devices and finite-time processes. J Appl Phys, 1996, 79:1191-1218

8 Bejan A. Entropy Generation Minimization. New York: CRC Press, 1995

9 Guo J F, Cheng L, Xu M T. Optimization design of shell-and-tube heat exchanger by entropy generation minimization and genetic algorithm. Appl Therm Eng, 2009, 29: 2954-2960

10 Guo J F, Cheng L, Xu M T. The entropy generation minimization based on the revised entropy generation number. Int J Exergy, 2010, 7: 607-629

11 Guo J F, Xu M T, Cheng L. The application of field synergy number in shell-and-tube heat exchanger optimization design. Appl Energ, 2009, 86: 2079-2087

12 Guo J F, Cheng L, Xu M T. Entransy dissipation number and its application to heat exchanger performance evaluation. Chinese Sci Bull, 2009, 54: 2708-2713

13 Guo Z Y, Zhu H Y, Liang X G. Entransy-A physical quantity describing heat transfer ability. Int J Heat Mass Transfer, 2007, 50: 2545-2556

14 Guo Z Y, Liu X B, Tao W Q, et al. Effectiveness-thermal resistance method for heat exchanger design and analysis. Int J Heat Mass Transfer, 2010, 53: 2877-2884

15 Chen L G, Wei S H, Sun F R. Constructal entransy dissipation minimization for 'volume-point' heat conduction. J Phys D: Appl Phys, 2008, 41: 195506

$16 \mathrm{Xu} \mathrm{M} \mathrm{T,} \mathrm{Chen} \mathrm{L,} \mathrm{Guo} \mathrm{J} \mathrm{F.} \mathrm{An} \mathrm{application} \mathrm{of} \mathrm{entransy} \mathrm{dissipation}$ theory to heat exchanger design (in Chinese). J Eng Thermophys, 2009, 30: 2090-2092

17 Bejan A. Entropy Generation Through Heat and Fluid Flow. New York: John Wiley \& Sons, 1982

18 Wang S P, Chen Q L, Zhang B J. An equation of entransy transfer and its application. Chinese Sci Bull, 2009, 54: 3572-3578

19 Han G Z, Guo Z Y. Physical mechanism of heat conduction ability dissipation and its analytical expression (in Chinese). Proc CSEE, 2007, 27: 98-102

20 Guo J F, Li M X, Xu M T, et al. The application of entransy dissipation theory in optimization design of heat exchanger. In: Proceedings of the 14th International Heat Transfer Conference, Washington, 2010

Open Access This article is distributed under the terms of the Creative Commons Attribution License which permits any use, distribution, and reproduction in any medium, provided the original author(s) and source are credited. 